\title{
Osmotic-stress-induced synthesis and degradation of inorganic polyphosphates in the alga Phaeodactylum tricornutum
}

\author{
José M. Leitão ${ }^{1,2}$, Bernd Lorenz ${ }^{1}$, Nilza Bachinski ${ }^{1,3}$, Christian Wilhelm ${ }^{4}$, \\ Werner E. G. Müller ${ }^{1}$, Heinz C. Schröder ${ }^{1, *}$ \\ ${ }^{1}$ Institut für Physiologische Chemie, Universität, Duesbergweg 6, D-55099 Mainz, Germany \\ ${ }^{2}$ Unidade de Ciencias e Tecnologias Agrarias, Universidade do Algarve, Campus de Gambelas, P-8000 Faro, Portugal \\ ${ }^{3}$ Departamento de Bioquímica, Instituto de Química, Centro de Tecnologia, Universidade Federal do Rio de Janeiro, \\ 21941-900 Rio de Janeiro, RJ, Brazil \\ ${ }^{4}$ Institut für Allgemeine Botanik, Universität, Müllerweg 6, D-55099 Mainz, Germany
}

\begin{abstract}
The potential role of inorganic polyphosphates in the response of algal cells to osmotic stress was investigated. We show that changes in polyphosphate metabolism of algae induced by osmotic stress can be easily determined by measuring the metachromatic shift of toludine blue produced by polyphosphate and by analysing the size of the extracted polyphosphate on urea/polyacrylamide gels. The amount and size of polyphosphate were found to differ considerably among different algal species. It is demonstrated that the alga Phaeodactylum tricornutum responds to hyperosmotic stress with a marked elongation of polyphosphate molecules and a decrease in the total amount of extractable polyphosphate, while exposure to hypoosmotic stress results in an increase in soluble shorter-chain polyphosphates and a rise in total polyphosphate content.
\end{abstract}

KEY WORDS: Polyphosphate - Osmotic stress P Polyphosphate metabolism $\cdot$ Algae $\cdot$ Phaeodactylum tricornutum

\section{INTRODUCTION}

Inorganic polyphosphates consisting of 3 to more than 1000 phosphate residues have been detected in many organisms, including bacteria, plants and animals (Kulaev 1979, Kulaev \& Vagabov 1983, Wood \& Clark 1988). The physiological function of inorganic polyphosphates is uncertain, although the presence of high-energy phosphoanhydride bonds suggests some role in energy metabolism. Polyphosphates may serve (1) as an energy source (Kornberg 1957), (2) as a phosphate reserve that can be mobilized under conditions of phosphate starvation (Kulaev 1979, Kulaev \& Vagabov 1983), (3) as metabolic regulators by chelat-

- Addressee for correspondence ing metal ions (Harold 1966), and (4) as substrate for certain sugar kinases (Pepin \& Wood 1986). In addition, it has been shown that polyphosphates are able to form channels with poly- $\beta$-hydroxybutyrate and $\mathrm{Ca}^{2+}$ in the plasma membranes of bacteria (Reusch \& Sadoff 1988).

Several enzymes have been shown to be involved in the synthesis and degradation of polyphosphates. Polyphosphate kinases catalyze the formation of polyphosphate from ATP in a reversible reaction (Ahn \& Kornberg 1990, Akiyama et al. 1992). Endopolyphosphatases cleave long-chain polyphosphates within the polyphosphate chain (Kritskii et al. 1972), while exopolyphosphatases hydrolyze polyphosphates to orthophosphate (Akiyama et al. 1993, Andreeva \& Okorokov 1993). Recently we purified a 28 kDa exopolyphosphatase from Saccharomyces 
cerevisiae to apparent homogeneity (Lorenz et al. 1994b).

Algae are able to accumulate large amounts of polyphosphate (Langen 1958, 1961, Kulaev 1979). It has been suggested that hydrolysis of polyphosphates in algae may provide a pH-stat mechanism to counterbalance alkaline stress. Cytoplasmic alkalinization of the unicellular alga Dunaliella salina induced by ammonium ions resulted in degradation of long-chain polyphosphates to tripolyphosphate. The hydrolysis of polyphosphates has been followed in vivo by ${ }^{31} \mathrm{P}$ nuclear magnetic resonance (NMR) spectroscopy and found to be correlated with the recovery of cytoplasmic pH (Pick et al. 1990). Using ${ }^{31} \mathrm{P}$ NMR spectroscopy, evidence has been presented that hypoosmotic shock of $D$. salina cells is followed by an immediate increase in the content of shorter polyphosphate chains, and an increased ATP level, while hyperosmotic shock results in an elongation of polyphosphate chains and a decrease in ATP level (Bental et al. 1990).

Detection of osmotic stress in natural phytoplankton populations and characterization of the state of osmotic adjustment, e.g. via polyphosphates, may be of global ecological importance, because it is known that the phytoplankton-dimethyl sulfide-cloud-climate feedback cycle is influenced by osmotic potential (Dickson \& Kirst 1987, Turner et al. 1988, Lawrence 1993)

In this study, we analyzed the effect of osmotic stress on the cellular content and chain lengths of inorganic polyphosphates in the alga Phaeodactylum tricornutum by determining the changes in the polyphosphateinduced metachromatic shift of the absorption maximum of toluidine blue and by sizing the extracted polyphosphate on urea/polyacrylamide gels.

\section{MATERIALS AND METHODS}

Algal cultures. Phaeodactylum tricornutum, Chlamydomonas reinhardtii, Cyclotella meninghiniana, Porphyridium cruentum, Chlorella fusca, and Anacystis sp. were grown in batch cultures on a rotary shaker (120 rpm) under illumination with white fluorescent lamps $\left(190 \mu \mathrm{E} \mathrm{m}^{-2} \mathrm{~s}^{-1}\right)$ at constant temperature $\left(18^{\circ} \mathrm{C}\right)$. The medium used for cultivation of $P$. tricornutum, $C$. meninghiniana, and $P$. cruentum was prepared from 11 of Bristol's solution (concentrations in $\mathrm{g} \mathrm{l}^{-1}: 0.25$ $\mathrm{NaNO}_{3}, 0.025 \mathrm{CaCl}_{2} \cdot 2 \mathrm{H}_{2} \mathrm{O}, 0.075 \mathrm{MgSO}_{4} \cdot \mathrm{H}_{2} \mathrm{O}, 0.075$ $\mathrm{K}_{2} \mathrm{HPO}_{4}, 0.175 \mathrm{KH}_{2} \mathrm{PO}_{4}, 0.025 \mathrm{NaCl}$ ) by addition of a drop of $1.0 \% \mathrm{FeCl}_{3}$ solution, $2 \mathrm{ml}$ of trace element solution and $40 \mathrm{ml}$ of soil extract. Trace element solution was prepared by mixing $20 \mathrm{ml}$ of Solution 1 (in $\mathrm{g} \mathrm{I}^{-1}$ : $0.5 \mathrm{ZnSO}_{4} \cdot 7 \mathrm{H}_{2} \mathrm{O}, 0.1 \mathrm{MnSO}_{4} \cdot \mathrm{H}_{2} \mathrm{O}, 0.5 \mathrm{H}_{3} \mathrm{BO}_{3}, 0.05$ $\mathrm{Co}\left(\mathrm{NO}_{3}\right)_{2} \cdot 6 \mathrm{H}_{2} \mathrm{O}, 0.05 \mathrm{Na}_{2} \mathrm{MoO}_{4} \cdot 2 \mathrm{H}_{2} \mathrm{O}, 0.05 \mathrm{CuSO}_{4}$.
$5 \mathrm{H}_{2} \mathrm{O}, 20$ EDTA) and $100 \mathrm{ml}$ of Solution 2 (in $\mathrm{g} \mathrm{l}^{-1}$ : $7 \mathrm{FeSO}_{4} \cdot 7 \mathrm{H}_{2} \mathrm{O}, 4 \mathrm{EDTA}$ ) after sterilization in an autoclave. Soil was extracted by boiling with distilled water in a pressure cooker for $1 \mathrm{~h}$, allowing it to stand overnight, boiling again with distilled water for $1 \mathrm{~h}$, centrifugation, and autoclaving of supernatant. The salinity of the medium (without soil extract) was $0.62 \%$ and the $\mathrm{pH}$ was 7.2

The medium used for cultivation of Chlamydomonas reinhardtii and Chlorella fusca has been described by Strotmann (1966), and that for Anacystis sp. by Staub (1961).

Algal cells (100 mg wet weight), growing logarithmically, were harvested by centrifugation $(2000 \times g$. $10 \mathrm{~min}$ ) and resuspended in $10 \mathrm{ml}$ of fresh medium adjusted to the desired $\mathrm{NaCl}$ concentration. After incubation for 5 to $60 \mathrm{~min}$ under shaking at room temperature, cells were harvested.

In some experiments Phaeodactylum tricornutum cultures were adapted to $0.5 \mathrm{M} \mathrm{NaCl}$ before shock treatment by growing them in $0.5 \mathrm{M} \mathrm{NaCl}$ for several generations.

Extraction and determination of polyphosphate content. Approximately $100 \mathrm{mg}$ (wet weight) of algal cells was pelleted in a microfuge tube, washed with water and ground with glass beads under cooling by dry ice. Polyphosphates were then extracted essentially as described by Clark et al. (1986). Step 1 extracts contain the short-chain acid-soluble polyphosphates, while Step 2 extracts represent the easily extractable, 'soluble' portion of long-chain polyphosphate and Step 3 extracts the remaining long-chain polyphosphate (Clark et al. 1986). Proteins were removed from Step 2 and 3 extracts by 1 extraction with phenol/chloroform $(1: 1 \mathrm{v} / \mathrm{v})$, followed by 3 successive extractions with chloroform.

For estimation of polyphosphate content, $10 \mu \mathrm{l}$ of the Step 2 and 3 extracts was added to $1 \mathrm{ml}$ of dye solution ( $6 \mathrm{mg} \mathrm{l}^{-1}$ of toluidine blue in $40 \mathrm{mM}$ acetic acid), and the change in absorbance due to the metachromatic effect was determined by measuring the absorbance at 530 and $630 \mathrm{~nm}$. A calibration curve was used which was obtained by measuring the metachromatic shift produced by various amounts of a polyphosphate standard with an average chain length of 35 phosphate residues. Absorption spectra were recorded with a Beckman DU-64 spectrophotometer.

Residual polyphosphate not extracted by Steps 2 and 3 was measured after acid hydrolysis at $100^{\circ} \mathrm{C}$ as described by Lohmann \& Langen (1956). The resulting orthophosphate was determined spectrophotometrically by adding $0.5 \mathrm{ml}$ of $2.5 \%$ ammonium molybdate in $2 \mathrm{M} \mathrm{HCI}$ and $100 \mu \mathrm{l}$ of $2 \mathrm{mM} 1$-amino-2-naphthol-4sulfonic acid to $1 \mathrm{ml}$ of sample. After $30 \mathrm{~min}$, the absorbance was measured at $700 \mathrm{~nm}$. 
Determination of polyphosphate size. The size of the extracted polyphosphate was determined by electrophoresis on $7 \mathrm{M}$ urea/16.5\% polyacrylamide gels $(30 \times 15 \times 0.3 \mathrm{~cm}$; ratio of bisacrylamide to acrylamide $1: 20)$ in $1 \times$ TBE $(90 \mathrm{mM}$ Tris, $90 \mathrm{mM}$ borate, $2.7 \mathrm{mM}$ EDTA; pH 8.3) (Clark \& Wood 1987, Lorenz et al. $1994 \mathrm{a}, \mathrm{b})$. The gels were electrophoresed at $9 \mathrm{~W}$ for 120 to 130 min until the sample dye, bromophenol blue, had migrated 11 to $12 \mathrm{~cm}$. For resolution of longchain polyphosphates, a $2 \%$ polyacrylamide/0.5\% agarose gel was used (Clark \& Wood 1987). Polyphosphate was detected by staining with o-toluidine blue $\mathrm{O}$ $(0.05 \%)$ in $25 \%$ methanol $/ 1 \%$ glycerol and destaining in $25 \%$ methanol $/ 5 \%$ glycerol. Polyphosphate standards of defined chain lengths were run in parallel. A semilog plot of distance migrated versus number of phosphate residues resulted in a straight line.

Protein assay. Protein concentrations were determined as described by Bensadoun \& Weinstein (1976) with bovine serum albumin as a standard.

Materials. Tripolyphosphate, tetrapolyphosphate, polyphosphate types $5,15,35$ and $75+$ (sodium salts, with an average chain length of 5, 15, 35 and 91 phosphate residues, respectively) and insoluble Maddrell salt (long-chain polyphosphate) were purchased from Sigma Chemical Co. (St. Louis, MO, USA).

Polyphosphate standards $\left(\mathrm{P}_{34}, \mathrm{P}_{63}, \mathrm{P}_{125}\right.$ and $\mathrm{P}_{200}$, consisting of $34,63,125$ and 200 phosphate residues, respectively) were prepared by fractionation of Sigma polyphosphate types 35 and $75+$ on a preparative urea/ polyacrylamide gel (Clark \& Wood 1987). Following electrophoresis, horizontal gel slices corresponding to the desired chain lengths were crushed in liquid nitrogen and extracted by shaking in $50 \mathrm{mM}$ Tris- $\mathrm{HCl}$ buffer ( $\mathrm{pH}$ 7.5) containing $0.15 \mathrm{M} \mathrm{NaCl}$ for $12 \mathrm{~h}$ at room temperature. Polyphosphate with an average chain length of approximately 800 phosphate residues was prepared by fractionation of solubilized Maddrell salt on a $2 \%$ polyacrylamide/0.8\% agarose gel. Maddrell salt was solubilized as described by Van Wazer (1958).

\section{RESULTS}

The metabolism of polyphosphate in Phaeodactylum tricornutum was studied by measuring the polyphosphate content in different polyphosphate fractions obtained by successive extractions. The method applied was based on the metachromasy induced by the polymer.

Fig. 1 shows a plot of the ratio of absorbance values at $530 \mathrm{~nm}$ to absorbance values at $630 \mathrm{~nm}$ as a function of the amount of polyphosphate for 3 commercial polyphosphate samples consisting of different chain lengths (Sigma polyphosphates types 15,35 and $75+$ ).

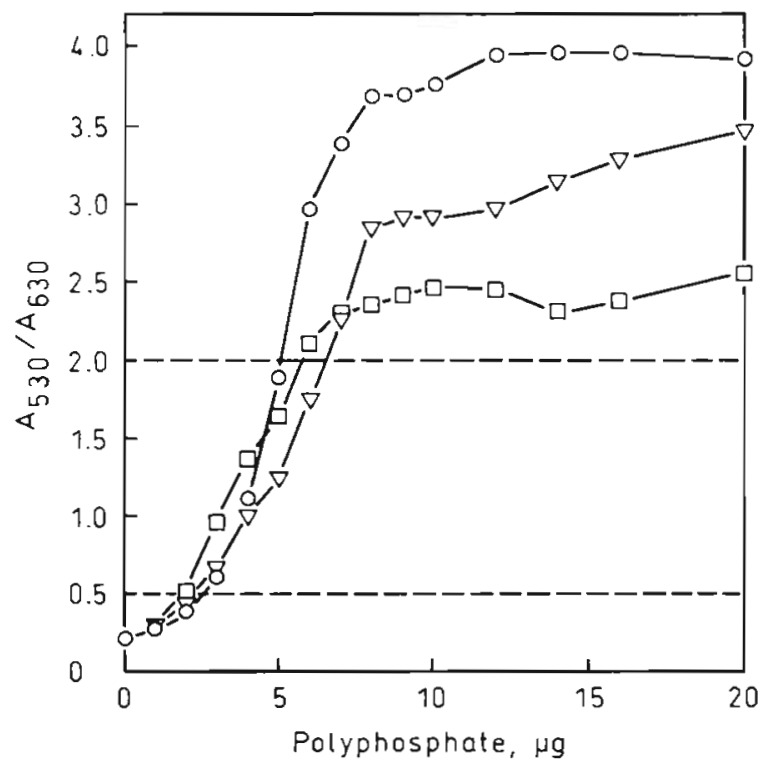

Fig. 1. Changes in the ratio of the absorbance at $530 \mathrm{~nm}$ to that at $630 \mathrm{~nm}$ of toluidine blue as a function of the amount of polyphosphate for different polyphosphate chain lengths. Various amounts of polyphosphates (Sigma types $15, \square ; 35, \nabla$, and $75+, 0)$ were added to $1 \mathrm{ml}$ of dye solution $\left(6 \mathrm{mg} \mathrm{l}^{-1}\right.$ of toluidine blue dissolved in $40 \mathrm{mM}$ acetic acid) and the absorbance values at $530 \mathrm{~nm}$ and $630 \mathrm{~nm}$ were determined. The $530 \mathrm{~nm} / 630 \mathrm{~nm}$ absorbance ratio was calculated and plotted versus the amount of polyphosphate

The curves were roughly linear within a limited range of $530 \mathrm{~nm} / 630 \mathrm{~nm}$ absorbance ratios. This range and the maximum intensities of the metachromatic reaction for various polyphosphate samples depended on the average chain lengths of the polymers. The maximum intensity for polyphosphate with average chain length 91 was higher than that for polyphosphate with average chain length 35, and the maximum intensity for polyphosphate with average chain length 35 was higher than for polyphosphate that with average chain length 15. Consequently, this method can be used for semi-quantitative measurements of polyphosphate, e.g. in a $530 \mathrm{~nm} / 630 \mathrm{~nm}$ absorbance-ratio range of 0.5 to 2.5 , provided the chain lengths of the polymers are $\geq 35$ phosphate residues. If the size of the polyphosphate sample is shorter, the range of $530 \mathrm{~nm} / 630 \mathrm{~nm}$ absorbance ratios allowing semi-quantitative measurements of the polymers becomes smaller, e.g. 0.5 to 2.0 for $P_{15}$. Polyphosphate samples with unknown chain lengths may be tested after determining the $530 \mathrm{~nm} /$ $630 \mathrm{~nm}$ absorbance ratios for successive dilutions of the samples and plotting the ratios versus titer of dilution. If the characteristics of the resulting curve conform to those of the curve for $\mathrm{P}_{35}$ (or $\mathrm{P}_{91}$ ), semi-quantitative measurements of polyphosphate using the calibration curve for $\mathrm{P}_{35}$ are possible. If the maximum intensity of 
Table 1 Polyphosphate content of different algal species. Polyphosphate was determined in Step 2 and Step 3 extracts. The polyphosphate content (mean $\pm \mathrm{SD}$ of 3 independent experiments) is given both in $\mu \mathrm{g} \mathrm{g}^{-1}$ wet wt of alga and $\mathrm{mg}$ $\mathrm{g}^{-1}$ of protein

\begin{tabular}{|c|c|c|}
\hline \multirow{2}{*}{$\begin{array}{c}\text { Extraction } \\
\text { step }\end{array}$} & \multicolumn{2}{|c|}{ Polyphosphate content } \\
\hline & $\mu \mathrm{g} \mathrm{g}^{-1}$ wet wt & $m g g^{-1}$ protein $^{a}$ \\
\hline \multicolumn{3}{|c|}{ Phaeodactylum tricornutum } \\
\hline 2 & $38.1 \pm 2.7$ & $1.19 \pm 0.08$ \\
\hline 3 & $10.3 \pm 1.1$ & $0.32 \pm 0.03$ \\
\hline \multicolumn{3}{|c|}{ Chlamydomonas reinhardtii } \\
\hline 2 & $27.7 \pm 3.2$ & $0.75 \pm 0.09$ \\
\hline 3 & $19.6 \pm 0.2$ & $0.53 \pm 0.01$ \\
\hline \multicolumn{3}{|c|}{ Cyclotella meninghiniana } \\
\hline 2 & $21.9 \pm 2.9$ & $0.61 \pm 0.08$ \\
\hline 3 & $20.5 \pm 4.2$ & $0.57 \pm 0.12$ \\
\hline \multicolumn{3}{|l|}{ Chlorella fusca } \\
\hline 2 & $1.8 \pm 1.1$ & $0.07 \pm 0.04$ \\
\hline 3 & $5.3 \pm 0.8$ & $0.20 \pm 0.03$ \\
\hline \multicolumn{3}{|l|}{ Anacystis sp. } \\
\hline 2 & $7.1 \pm 0.5$ & $0.22 \pm 0.02$ \\
\hline 3 & $24.3 \pm 1.6$ & $0.74 \pm 0.05$ \\
\hline \multicolumn{3}{|c|}{$\begin{array}{l}{ }^{2} \text { Calculated from the amount of protein harvested, which } \\
\text { was determined in parallel assays as follows (given in } g \\
\text { protein } \mathrm{g}^{-1} \text { wet wt of alga): P. tricornutum, } 0.032 ; C \text {. rein } \\
\text { hardtii, } 0.037 ; \text { C. meninghiniana, 0.036; C. fusca, } 0.026 \\
\text { Anacystis sp., } 0.033\end{array}$} \\
\hline
\end{tabular}

the metachromatic reaction is lower than that of $P_{35}$, calibration curves obtained with shorter-chain polyphosphate standards yielding curves with similar characteristics may be used for estimation of polyphosphate content. Polyphosphates with chain lengths $\leq 5$ phosphate residues did not react metachromatically.

Table 1 shows the polyphosphate content determined in Step 2 and Step 3 extracts of different species of algae. The amount of soluble, medium- to longchain polyphosphate (Step 2 fraction) was highest in Phaeodactylum tricornutum, followed by Chlamydomonas reinhardtii and Cyclotella meninghiniana, while only moderate to small amounts of this polyphosphate fraction were present in Anacystis sp. and Chlorella fusca. On the other hand, $C$. reinhardtii, Anacystis sp. and $C$. meninghiniana were found to contain higher quantities of less soluble long-chain polyphosphates (Step 3 fraction) than P. tricornutum; the smallest amounts were found in C. fusca. Determination of the amount of acid hydrolyzable phosphate remaining in the residual pellets revealed that $\geq 95 \%$ of the total polyphosphate was extracted by Steps 1 to 3 (results not shown).

The size of the extracted polyphosphate was analyzed by electrophoresis on urea/polyacrylamide gels, followed by staining with toluidine blue. It was found that polyphosphate extractable by Step 2 from Phaeo-

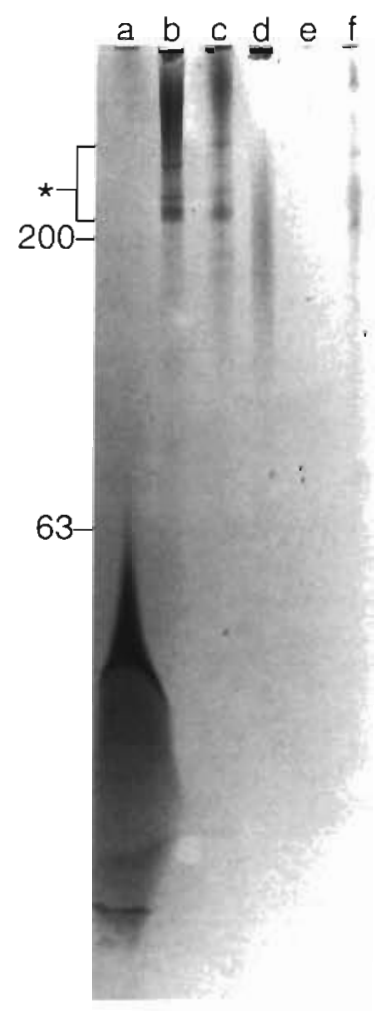

Fig. 2. Size of polyphosphate extracted from different species of algae (Step 2 fraction). The entire amount of polyphosphate extracted by Step 2 from $100 \mathrm{mg}$ wet wt of the algae listed below was applied to the gel (the corresponding amount of protein is given for each species in parentheses). Lanes: (a) Phaeodactylum tricornutum (3.2 mg); (b) Chlamydomonas reinhardtii $(3.7 \mathrm{mg})$; (c) Cyclotella meninghiniana $(3.6 \mathrm{mg})$; (d) Porphyridium cruentum $(2.3 \mathrm{mg}$ ); (e) Chlorella fusca (2.6 mg); (f) Anacystis sp. (3.3 mg). Analysis of chain lengths of extracted polyphosphate was performed by electrophoresis on a $7 \mathrm{M}$ urea/ $16.5 \%$ polyacrylamide gel. The migration positions of polyphosphate standards (number of phosphate residues) are indicated. The gel was stained with toluidine blue. Asterisk ( ${ }^{\prime}$ ) indicates nucleic acid bands. The aberration in Lane a is caused by salt

dactylum tricornutum mainly consisted of polyphosphate molecules with chain lengths of up to 60 orthophosphate residues (Fig. 2, Lane a), while Step 2 extracts from Chlamydomonas reinhardtii, Cyclotella meninghiniana, Porphyridium cruentum, and Anacystis sp. (Fig. 2, Lanes $b$ to $d, f$ ) contained longer polymers (above $\mathrm{P}_{200}$ size marker). On the other hand, less soluble long-chain polyphosphates (Step 3 fraction, with chain lengths greater than 200) remaining stacked at the top of the $15 \%$ polyacrylamide gel were present in $C$. reinhardtii, C. meninghiniana, $P$. cruentum, and Anacystis sp., while polyphosphate in Step 3 extracts from $P$. tricornutum was significantly shorter (not shown). Only small amounts of polyphosphate were detected in Step 2 and Step 3 extracts from 


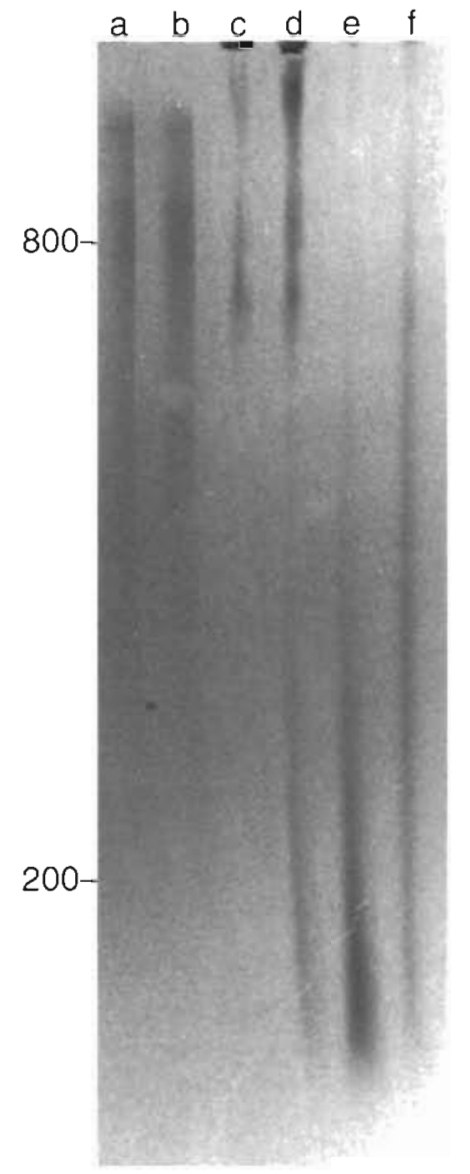

Fig. 3. Size of long-chain polyphosphates in Step 3 extracts from different species of algae. Separation was performed on a $2 \%$ polyacrylamide $/ 0.5 \%$ agarose gel. The entire amount of polyphosphate extracted by Step 3 from $100 \mathrm{mg}$ wet wt of algae (except for Chlorella fusca: $500 \mathrm{mg}$ wet wt) was applied to the gel. Lanes: (a) synthetic polyphosphate sample with average chain length of approximately 800 phosphate residues $(3 \mu \mathrm{g})$; (b) the same synthetic polyphosphate sample $(3 \mu \mathrm{g})$ added to Phaeodactylum tricornutum cultures $(100 \mathrm{mg}$ wet $w t)$, which do not contain significant amounts of highly polymerized polyphosphates, and isolated by the same procedure, (c) Chlamydomonas reinhardtii; (d) Cyclotella meninghunıana; (e) C. fusca; (f) Anacystis sp. The amount of protein corresponding to $100 \mathrm{mg}$ wet wt of each alga and further details are given in the legend to Fig. 2

Chlorella fusca (Fig. 2, Lane e). The long-chain polyphosphates extracted by Step 3 could be resolved in $2 \%$ polyacrylamide $10.5 \%$ agarose gel (Fig. 3, Lanes $\mathrm{c}$ to f). In a control assay it was determined that a synthetic polyphosphate sample (average chain length of approximately 800 phosphate residues) added to algal culture and isolated by the same procedure was not degraded (Fig. 3, Lanes a and b).

To study the effect of hyperosmotic shock on Phaeodactylum tricornutum, the $\mathrm{NaCl}$ concentration in algal cultures at logarithmic phase was raised from $0.41 \mathrm{mM}$ to $1 \mathrm{M}$ for 5 to $60 \mathrm{~min}$. Control cultures were maintained for the same period of time in standard medium. As summarized in Table 2, the amount of polyphosphate in Step 2 extracts from $P$. tricornutum, containing the soluble fraction of polyphosphate, markedly decreased (by $67 \%$ ) following hyperosmotic shock (20 min), while less soluble long-chain polyphosphates present in Step 3 extracts accumulated (increase of $131 \%$ ). This indicates that hyperosmotic shock induces an increase in the chain lengths of polyphosphates. The total polyphosphate content (sum of polyphosphate extracted by Steps 2 and 3) decreased. The formation of longer-chain polyphosphates is shown in Fig. 4, evidenced by comparing Lane b (Step 3 extracts of non-shocked algae) and Lane d (Step 3 extracts of algae shocked with $1 \mathrm{M} \mathrm{NaCl}$ for $20 \mathrm{~min}$ ). On the other hand, shorter-chain polyphosphates extracted by Step 2 markedly decreased; compare Lane a (non-shocked algae) with Lane c ( $1 \mathrm{M} \mathrm{NaCl}$ shock). From this result we conclude that exposure of $P$. tricornutum to hyperosmotic shock causes an increase in the average length of polyphosphate chains, most likely due to an increase in long-chain polyphosphates at the expense of shorter-chain polyphosphates.

Hypoosmotic shock was induced by incubating logarithmically growing cultures at $0 \mathrm{M} \mathrm{NaCl}$ for 5 to $60 \mathrm{~min}$. It was found that hypoosmotic shock was fol-

Table 2. Phaeodactylum tricornutum. Effect of hyperosmotic shock and hypoosmotic shock on polyphosphate content (mean $\pm \mathrm{SD}$ of 3 independent experiments). Algae were subjected to hyperosmotic shock $(1 \mathrm{M} \mathrm{NaCl})$ or hypoosmotic shock $(0 \mathrm{M} \mathrm{NaCl})$ for 5 to $60 \mathrm{~min}$. In one series of experiments (values given in parentheses), algae were adapted to $0.5 \mathrm{M}$ $\mathrm{NaCl}$ before shock treatment. Polyphosphate was determined in Step 2 and Step 3 extracts

\begin{tabular}{|cccc}
$\begin{array}{c}\text { Extraction } \\
\text { step }\end{array}$ & Treatment & $\begin{array}{c}\text { Polyphosphate content } \\
\left(\mu \mathrm{g} \mathrm{g}^{-1} \text { wet } w t\right)\end{array}$ \\
\hline 2 & - & $38.1 \pm 2.7$ & $(31.4 \pm 2.9)$ \\
3 & - & $10.3 \pm 1.1$ & $(21.2 \pm 2.2)$ \\
2 & $1 \mathrm{M} \mathrm{NaCl}, 5 \mathrm{~min}$ & $30.8 \pm 2.3$ & \\
3 & $1 \mathrm{M} \mathrm{NaCl}, 5 \mathrm{~min}$ & $13.4 \pm 3.3$ & \\
2 & $1 \mathrm{M} \mathrm{NaCl}, 20 \mathrm{~min}$ & $12.7 \pm 1.8$ & $(13.0 \pm 2.0)$ \\
3 & $1 \mathrm{M} \mathrm{NaCl}, 20 \mathrm{~min}$ & $23.8 \pm 3.1$ & $(30.1 \pm 1.9)$ \\
2 & $1 \mathrm{M} \mathrm{NaCl} 60 \mathrm{~min}$ & $10.6 \pm 2.2$ & \\
3 & $1 \mathrm{M} \mathrm{NaCl}, 60 \mathrm{~min}$ & $20.8 \pm 1.1$ & \\
2 & $0 \mathrm{M} \mathrm{NaCl}, 5 \mathrm{~min}$ & $44.6 \pm 5.1$ & \\
3 & $0 \mathrm{M} \mathrm{NaCl}, 5 \mathrm{~min}$ & $12.9 \pm 1.0$ & \\
2 & $0 \mathrm{M} \mathrm{NaCl}, 20 \mathrm{~min}$ & $55.6 \pm 4.0$ & $(60.7 \pm 5.5)$ \\
3 & $0 \mathrm{M} \mathrm{NaCl}, 20 \mathrm{~min}$ & $14.3 \pm 0.5$ & $(15.5 \pm 1.7)$ \\
2 & $0 \mathrm{M} \mathrm{NaCl}, 60 \mathrm{~min}$ & $53.2 \pm 3.9$ & \\
3 & $0 \mathrm{M} \mathrm{NaCl}, 60 \mathrm{~min}$ & $15.0 \pm 2.4$ &
\end{tabular}

"The wet weight of algae drastically changed following hyperosmotic shock and hypoosmotic shock, due to cell shrinkage and swelling, respectively. Therefore, values are based on wet weight of algae before shock treatment 
a $\quad b \quad c c c$

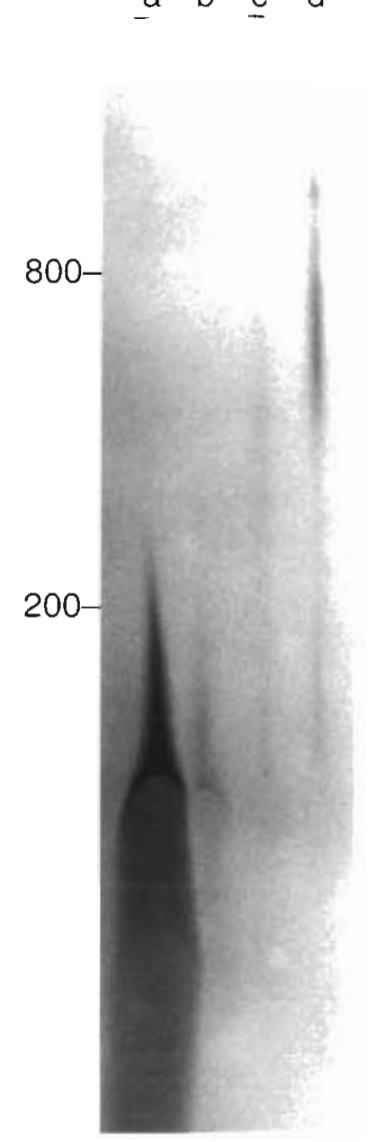

Fig. 4. Phaeodactylum tricornutum. Changes in the size of polyphosphate extracted from algae subjected to hyperosmotic shock. The size of the polyphosphate was determined in Step 2 and Step 3 extracts $20 \mathrm{~min}$ after hyperosmotic shock. Equal amounts of extracts corresponding to $100 \mathrm{mg}$ wet weight of alga before shock treatment were applied to each lane. Lanes: (a) Step 2 extract from non-shocked control; (b) Step 3 extract from non-shocked control; (c) Step 2 extract from algae subjected to $1 \mathrm{M} \mathrm{NaCl}$ shock; (d) Step 3 extract from algae subjected to $1 \mathrm{M} \mathrm{NaCl}$ shock. For further details, see legend to Fig. 2

lowed by a substantial increase in the amount of shorter polyphosphate chains (Step 2 fraction; Table 2) but also by a slight increase in the amount of longchain polyphosphates (Step 3 fraction) and an elongation of polyphosphate chains in both Step 2 (Fig 5 , Lanes b and c) and Step 3 extracts (Fig. 5, Lanes d and e). It should be noted that this effect was already detectable at the low $\mathrm{NaCl}$ concentration $(0.41 \mathrm{mM})$ present in the medium used for cultivating Phaeodactylum tricornutum. Fig. 5, Lane a shows, for comparison, the size of Sigma polyphosphate type 35, which has an average chain length of 35 , but actually consists of a heterogeneous mixture of polyphosphates from 3 to more than 100 phosphate residues in length.

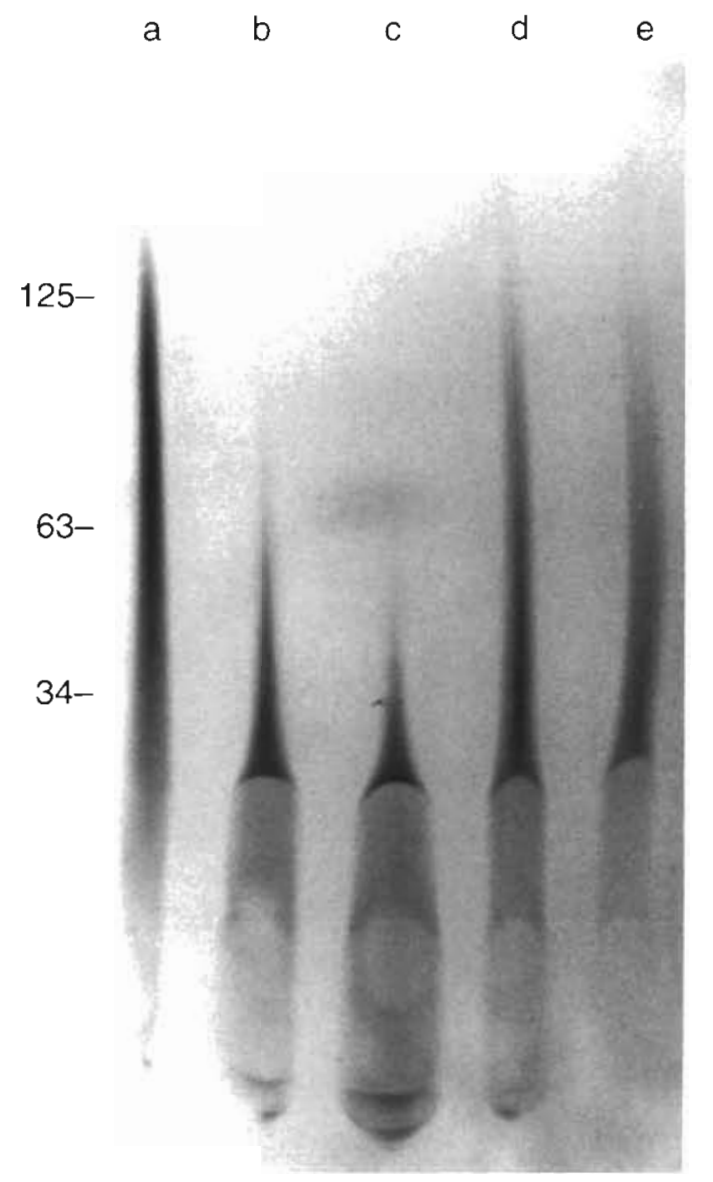

Fig. 5. Phaeodactylum tricornutum. Size of polyphosphate extracted from algae following hypoosmotic shock. Lanes: (a) commercial polyphosphate with average chain length of 35 phosphate residues (Sigma); (b) Step 2 extract, $20 \mathrm{~min}$ at $0 \mathrm{M}$ $\mathrm{NaCl}_{i}$ (c) Step 2 extract, 20 min normal medium; (d) Step 3

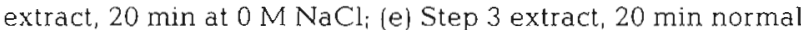
medium. The aberrations in Lanes $b$ to e are due to salt. For further details, see legend to Fig. 2

Phaeodactylum tricornutum cultures which had been adapted to a higher salt concentration $(0.5 \mathrm{M} \mathrm{NaCl})$ responded to hypoosmotic shock even more strongly. The increase in the amount of shorter polyphosphate chains (Step 2 fraction) following hypoosmotic shock (20 min) was about 2 -fold higher $(93 \%$ compared to $46 \%$ ) in algae adapted to $0.5 \mathrm{M} \mathrm{NaCl}$ than in algae grown in normal medium (Table 2). On the other hand, the increase in the amount of longer-chain polyphosphates (Step 3 fraction) following hyperosmotic shock was lower ( $42 \%$ compared to $131 \%$ ) (Table 2 ).

Time course experiments revealed that elongation of polyphosphate chains following hyperosmotic shock and an increase in the content of shorter polyphosphate chains following hypoosmotic shock had already occurred 5 min after induction of shock and remained constant for at least $1 \mathrm{~h}$ (Table 2). 


\section{DISCUSSION}

The development of simple methods for monitoring stress-caused effects in living organisms is urgently needed in environmental research. In this report we show that changes in polyphosphate metabolism of algae induced by osmotic stress can be easily determined by examining the metachromatic reaction and sizing the extracted polyphosphate on urea/polyacrylamide gels.

We were able to study the polyphosphate content in different polyphosphate fractions and changes caused by osmotic stress in the diatom Phaeodactylum tricornutum, and compared them with those in other algal species. The procedure we used for extraction of polyphosphate has been shown to avoid degradation of long-chain polyphosphates (Clark et al, 1986), while other procedures previously employed for isolation of polyphosphate from algae are based on rather drastic methods, such as extraction with hot perchloric acid or alkali (Langen \& Liss 1958, Harold 1963), causing hydrolysis of polyphosphate (Clark et al. 1986). Under these conditions, polyphosphate could be detected, for example, only in the red and green algae Ceramium sp., Enteromorpha sp. and Cladophora sp. but not in the brown algae Fucus sp., Ectocarpus sp. and Pylaiella sp. (Langen 1958, 1961).

The amount of polyphosphate present was measured by the metachromatic reaction (Kornberg et al. 1956, Griffin et al. 1965, Lorenz et al. 1994b). Polyphosphates, being negatively charged polyelectrolytes, are known to induce a shift in the absorption maximum of toluidine blue from ca 630 to ca $530 \mathrm{~nm}$. Within a limited range the change in the $530 \mathrm{~nm} / 630 \mathrm{~nm}$ absorbance ratio is roughly proportional to the amount of polyphosphate. However, the upper limit of this range depends on the chain length of the polymer. On an equimass basis, shorter-chain polyphosphates were found to be less capable of producing a metachromatic reaction than the longer polymers. Thus, the maximum intensity of the metachromatic reaction was highest for polyphosphates of average chain length 91 and above, and increasingly lower for polyphosphates of average chain lengths 35 and 15 . Consequently, the range of $530 \mathrm{~nm} / 630 \mathrm{~nm}$ absorbance ratios that are proportional to the amount of polyphosphate gradually decreases with decreasing chain length $\left(\mathrm{P}_{91}: 530 \mathrm{~nm} / 630 \mathrm{~nm}\right.$ absorbance ratio $=0.5$ to $3.5 ; \mathrm{P}_{35}: 0.5$ to $2.5 ; \mathrm{P}_{15}: 0.5$ to 2.0). Therefore, the metachromatic reaction can be employed for semi-quantitative measurements of polyphosphate at a $530 \mathrm{~nm} / 630 \mathrm{~nm}$ absorbance ratio between 0.5 and 2.0 provided the chain length of the polymer is greater than 15 phosphate residues.

It should be noted that the procedure presented here is simple compared to NMR spectroscopy and does not require expensive equipment. The results obtained showed a high correlation with those obtained in NMR studies (Bental et al. 1990; see below).

A high polyphosphate content was found in Step 2 extracts of Phaeodactylum tricornutum, Chlamydomonas reinhardtii and Cyclotella meninghiniana, while only moderate amounts of soluble long-chain polyphosphates were present in the green and cyanobacterial species. On the other hand, C. reinhardtii, Anacystis sp. and C. meninghiniana contained higher quantities of less soluble long-chain polyphosphate (Step 3 fraction) than P. tricornutum. Only small amounts of polyphosphate were extracted from Chlorella fusca.

In our study we analysed the chain lengths of the extracted polyphosphate on urea/polyacrylamide sequencing gels. This method has been shown to be applicable in the $\mu \mathrm{g}$ range (Robinson et al. 1984, Pepin \& Wood 1986, Robinson \& Wood 1986), while other procedures used for determining the chain lengths of polyphosphate, e.g. NMR (Rao et al. 1985) and titration (Liss \& Langen 1960), require higher amounts of polyphosphate and cannot be applied to very long polymers (Clark \& Wood 1987). It was found that Phaeodactylum tricornutum mainly contains shorterchain polyphosphates, while Chlamydomonas reinhardtil, Cyclotella meninghiniana, Porphyridium cruentum, and Anacystis sp. possess only the more highly polymerized fractions.

Synthesis and degradation of inorganic polyphosphates might allow the intracellular osmotic pressure to be adjusted to the extracellular osmotic pressure. Our results show that different polyphosphate fractions in algae respond differentially to osmotic stress. Exposure of Phaeodactylum tricornutum to hyperosmotic shock resulted in an increase in the amount of long-chain polyphosphates and a decrease in the amount of shorter-chain polyphosphates. The total polyphosphate content decreased. From these results we conclude that hyperosmotic shock is associated with an elongation of polyphosphates at the expense of shorter polyphosphate chains. It is possible that the shorter-chain polyphosphates are used for production of ATP via polyphosphate kinase during energy-consuming adaptation to increased osmotic stress. From the results in Table 2 (incubation at $1 \mathrm{M} \mathrm{NaCl}$ for $20 \mathrm{~min}$ ), it can be estimated that $0.32 \mu \mathrm{mol}$ of ATP $\mathrm{g}^{-1}$ wet weight of alga could have been generated by hydrolysis of polyphosphate present in the Step 2 fraction. However, part of the ATP produced $(0.17 \mu \mathrm{mol})$ would be needed again for the synthesis of longer polyphosphate chains.

In contrast, hypoosmotic shock was found to be associated with an accumulation of shorter-chain polyphosphates. But since the amount of long-chain polyphos- 
phates does not decrease but also increases following hypoosmotic shack (Table 2), a significant amount of ATP $\left(0.26 \mu \mathrm{mol} \mathrm{g}^{-1}\right.$ wet weight) would be consumed for synthesis of polyphosphate. Taking together these considerations and previously published results (Bental et al. 1990) showing a decrease in ATP level following hyperosmotic shock and an increase in ATP level following hypoosmotic shock, it is possible to assume that synthesis and degradation of inorganic polyphosphate during osmotic shock help algal cells to adjust their intracellular ATP level to normal. However, it should be noted that these calculations do not take into consideration the fact that different pools of polyphosphate exist in the cell which are localized in different cellular compartments (Kulaev \& Vagabov 1983) and may change differently during osmotic stress.

Elongation of polyphosphate chains following hyperosmotic shock and increase in the content of shorter polyphosphate chains following hypoosmotic shock are dynamic events and occurred as rapidly as $5 \mathrm{~min}$ after induction of shock. They remained constant for at least $1 \mathrm{~h}$.

These data support previous results obtained with high-resolution NMR (Bental et al. 1990). However, additional studies were required to clarify whether the observed changes in polyphosphate were due to alterations in polyphosphate chain lengths or to a change in the mobility and packing of the polyphosphate molecules, which may occur due to water influx and efflux following hypoosmotic shock and hyperosmotic shock, respectively (Bental et al. 1990).

The polyphosphate content in algae has also been shown to change during growth (Smillie \& Krotkov 1960) and to be modulated by light (Miyachi et al. 1964, Okuntsov \& Grebennikov 1977) and oxygen (Ullrich 1970). Exponentially growing cells have a low polyphosphate content, while high amounts of polyphosphates are present in older cultures. Young cells of Acetabularia crenulata have been reported to accumulate mainly acid-soluble polyphosphates, while only small amounts of salt-soluble, long-chain polyphosphates could be detected (Kulaev et al. 1975). Different polyphosphate fractions in Chlorella sp. were found to change differentially in the dark and in the light, and in the presence and absence of phosphate in the medium (Miyachi 1962, Kanai et al. 1963, Miyachi et al. 1964). A hypercompensation effect, i.e. accumulation of large amounts of polyphosphate, was observed when Scenedesmus quadricauda was grown on a phosphate-containing medium following phosphorus starvation (Overbeck 1962a, b)

At present it is unknown which processes are involved in the regulation of polyphosphate metabolism in algae. In preliminary studies we could identify both a polyphosphate kinase and an exopolyphospha- tase activity in Phaeodactylum tricornutum (authors' unpubl. results). Polyphosphate kinase and polyphosphatase activity has also been detected in Chlorella $\mathrm{sp}$ (Iwamura \& Kuwashima 1964) and Acetabularia mediterranea (Rubtsov \& Kulaev 1977). Polyphosphate glucokinase seems to be absent in algae (Uryson \& Kulaev 1970).

Polyphosphate metabolism of marine organisms has also attracted special attention in environmental research. It is known that waters containing low concentrations of phosphorus may suffer from a massive 'bloom' of cyanobacteria when they become polluted by detergents containing large quantities of phosphate (e.g. sodium tripolyphosphate). Under the conditions created in a phosphorus-rich medium after phosphorus starvation, cyanobacteria start to grow and to accumulate large amounts of polyphosphates (a phenomenon called 'polyphosphate overplus') (Kulaev 1979, Kulaev \& Vagabov 1983). Our results show that diatoms and green algae are also useful models for studying the effect of stress on polyphosphate metabolism of organisms in marine environments.

It is known that salinity markedly influences the concentrations of dimethyl sulfide and dimethyl sulfoniopropionate in nearshore waters (Turner et al. 1988). Dimethyl sulfide is formed from dimethyl sulfoniopropionate, a compound produced by algae, and is released into the atmosphere where it is an important factor in cloud formation (Lawrence 1993). Therefore, determination of the state of osmotic adjustment in natural phytoplankton populations, e.g. via polyphosphates, may be an important objective. The methods presented here for determining the content and degree of polymerization of polyphosphates are simple and inexpensive, and may also be useful for field applications which could provide information regarding stress levels in natural phytoplankton populations.

Acknowledgements. This work was supported by grants from the Bundesministerium für Forschung und Technologie (0319207 A8; AI 02 II-032-87\}. J.M.L. was the recipient of a fellowship from the Junta Nacional de Investigação Científica (BPD 128). We thank Dr 1. S. Kulaev (Academy of Sciences, Pushchino, Moscow Region, Russia) for helpful discussions.

\section{LITERATURE CITED}

Ahn K. Kornberg A (1990) Polyphosphate kinase from Escherichia coli. Purification and demonstration of a phosphoenzyme intermediate. J biol Chem 265:11734-11739

Akiyama M, Crooke E, Kornberg A (1992) The polyphosphate kinase gene of Escherichia coli. Isolation and sequence of the ppk gene and membrane location of the protein. J biol Chem 267:22556-22561

Akiyama M, Crooke E, Kornberg A (1993) An exopolyphosphatase of Escherichia coli. The enzyme and its ppx gene in a polyphosphate operon. J biol Chem 268:633-639 
Andreeva NA, Okorokov LA (1993) Purification and characterization of highly active and stable polyphosphatase from Saccharomyces cerevisıae cell envelope. Yeast 9: $127-139$

Bensadoun A, Weinstein D (1976) Assay of proteins in the presence of interfering materials. Analyt Biochem 70: 241-250

Bental M, Pick U, Avron M, Degani H (1990) Metabolic studies with NMR spectroscopy of the alga Dunaliella salina trapped within agarose beads. Eur J Biochem 188: $111-116$

Clark JE, Beegen H, Wood HG (1986) Isolation of intact chains of polyphosphate from Propionibacterium shermanii grown on glucose or lactate. $J$ Bacteriol 168: $1212-1219$

Clark JE, Wood HG (1987) Preparation of standards and determination of sizes of long-chain polyphosphates by gel electrophoresis. Analyt Biochem 161:280-290

Dickson DMJ, Kirst GO (1987) Osmotic adjustment in marine eukaryotic algae: the role of inorganic ions, quaternary ammonium, tertiary sulphonium and carbohydrate solutes. New Phytol 106:645-655

Griffin JB, Davidian NM. Penniall R (1965) Studies on phosphorus metabolism by isolated nuclei. VII. Identification of polyphosphate as a product. J biol Chem 240:4427-4434

Harold FM (1963) Inorganic polyphosphate of high molecular weight from Aerobacter aerogenes. J Bacteriol 86: $885-887$

Harold FM (1966) Inorganic polyphosphates in biology: structure, metabolism, and function. Bacteriol Rev 30: $772-794$

lwamura T, Kuwashima S (1964) Formation of adenosine-5'triphosphate from polyphosphate by a cell-free extract from Chlorella. J gen appl Microbiol 10:83-86

Kanai R, Miyachi S, Miyachi S (1963) Light-induced formation and mobilization of polyphosphate ' $\mathrm{C}$ ' in Chlorella cells. In: Tamiya $\mathrm{H}$ (ed) Microalgae and photosynthetic bacteria. University of Tokyo Press, Tokyo, p 613-618

Kornberg A, Kornberg SR, Simms ES (1956) Metaphosphate synthesis by an enzyme from Escherichia coli. Biochim Biophys Acta 20:215-227

Kornberg SR (1957) Adenosine triphosphate synthesis from polyphosphate by an enzyme from Escherichia coli. Biochim Biophys Acta 26:294-300

Kritskii MS, Chernysheva EK, Kulaev is (1972) Polyphosphate depolymerase activity in cells of the fungus Neurospora crassa. Biokhimiya 37:983-990 (in Russian)

Kulaev IS (1979) The biochemistry of inorganic polyphosphates. John Wiley \& Sons, Inc, New York

Kulaev IS, Rubtsov PM, Brommer B, Yazykov AI (1975) Polyphosphates of high-molecular weight in the course of growth of Acetabularia crenulata. Fiziol Rast 22: $537-543$

Kulaev IS, Vagabov VM (1983) Polyphosphate metabolism in microorganisms. Adv microb Physiol 24:83-171

Langen P (1958) Über Polyphosphate in Ostsee-Algen. Acta biol med germanica 1:368-372

Langen P (1961) Über Unterschiede im Gehalt an labilem Phosphat zwischen Rot- und Braunalgen. Pubbl Staz zool Napoli 32:130-133

Langen P, Liss E (1958) Über Bildung und Umsatz der Polyphosphate der Hefe. Biochem Z 330: 455-466

Lawrence MG (1993) An empirical analysis of the strength of the phytoplankton-dimethyl sulfide-cloud-climate feedback cycle. J geophys Res 98:20663-20673

Liss E, Langen P (1960) Über ein hochmolekulares Polyphosphat der Hefe. Biochem Z 333:193-201
Lohmann $K$, Langen P (1956) Untersuchungen an den kondensierten Phosphaten der Hefe. Biochem Z 328:1-11

Lorenz B, Marme S, Müller WEG, Unger K, Schröder HC (1994a) Preparation and use of polyphosphate-modified zirconia for purification of nucleic acids and proteins. Analyt Biochem 216:118-126

Lorenz. B, Müller WEG, Kulaev IS, Schroder HC (1994b) Purffication and characterization of an exopolyphosphatase from Saccharomyces cerevisiae. J biol Chem 269: 22198-22204

Miyachi S (1962) Turnover of phosphate compounds in Chiorella cells under phosphate deficiency in darkness. Plant Cell Physiol 3:1-4

Miyachi S, Kanai R, Mihara S, Miyachi S, Aoki S (1964) Metabolic roles of inorganic polyphosphates in Chlorella cells. Biochim Biophys Acta 93:625-634

Okuntsov MM, Grebennikov AS (1977) Effect of light on the content of inorganic polyphosphates and some organophosphorus compounds in Chlorella pyrenoidosa Chick. Biokhimiya 42:21-25 (in Russian)

Overbeck $\mathrm{J}$ (1962a) Investigations on the phosphate content of green algae. I. Phosphate content and rhythm of reproduction of Scenedesmus quadricauda in its natural habitat. Arch Hydrobiol 58:162-209

Overbeck J (1962b) Phosphate levels of green algae. III. The behavior of cell fractions of Scenedesmus quadricauda in daily cycles under various illumination conditions and by various phosphate compounds. Arch Mikrobiol 41: $11-26$

Pepin CA, Wood HG (1986) Polyphosphate glucokinase from Propionibacterium shermanii. Kinetics and demonstration that the mechanism involves both processive and nonprocessive type reactions. J biol Chem 261:4476-4480

Pick U, Bental M, Chitlaru E, Weiss M (1990) Polyphosphatehydrolysis - a protective mechanism against alkaline stress? FEBS Lett 274:15-18

Rao NN, Roberts MF, Torriani A (1985) Amount and chain length of polyphosphates from Escherichia coli depend on cell growth conditions. J Bacteriol 162:242-247

Reusch RN, Sadoff HL (1988) Putative structure and functions of a poly- $\beta$-hydroxybutyrate/calcium polyphosphate channel in bacterial plasma membranes. Proc Natl Acad Sci USA 85:4176-4180

Robinson NA, Goss NH, Wood HG (1984) Polyphosphate kinase from Propionibacterium shermanii: formation of an enzymatically active insoluble complex with basic proteins and characterization of synthesized polyphosphate Biochem int 8:757-769

Robinson NA, Wood HG (1986) Polyphosphate kinase from Propionibacterium shermanii. Demonstration that the synthesis and utilization of polyphosphate is by a processive mechanism. J biol Chem 261:4481-4485

Rubtsov PM, Kulaev IS (1977) Some pathways of biosynthesis and degradation of polyphosphates from the green algae Acetabularia mediterranea. Biokhimiya 42:1083-1089 (in Russian)

Smillie RM, Krotkov G (1960) Phosphorus-containing compounds in Euglena gracilis grown under different conditions. Arch Biochem Biophys 89:83-90

Staub R (1961) Ernährungsphysiologisch-autökologische Untersuchungen an der planktischen Blaualge Oscillatoria rubescens DC. Thesis. Schweiz Z Hydrol 23:116

Strotmann H (1966) Kinetische Untersuchungen an Teilschritten der Nitratreduktion von Chlorella im Licht. Thesis, Johann-Wolfgang Goethe University, Frankfurt

Turner SM, Malin G, Liss P, Harbour DS, Holligan PM (1988) The seasonal variation of dimethyl sulfide and dimethyl 
sulfoniopropionate concentrations in nearshore waters. Limnol Oceanogr 33:364-375

Ulirich WR (1970) Zur Wirkung von Sauerstoff auf die ${ }^{32} \mathrm{P}$ Markierung von Polyphosphaten und organischen Phosphaten bei Ankistrodesmus braunii im Licht. Planta 90:272 Uryson SO, Kulaev IS (1970) Glucokinase activity of some

This article was submitted to the editor green and blue-green algae. Biokhimiya 35:601-603 (in Russian]

Van Wazer JR (1958) Phosphorus and its compounds, Vol 1. Interscience Publishers, New York, p 669-672

Wood HG, Clark JE (1988) Biological aspects of inorganic polyphosphates. Ann Rev Biochem 57: 235-260

Manuscript first received: September 16, 1994 Revised version accepted: January 23, 1995 